\title{
Per Large Square Neubauer Chamber
}

National Cancer Institute

\section{Source}

National Cancer Institute. Per Large Square Neubauer Chamber. NCI Thesaurus. Code C130187.

A unit of measure equal to the instances of an entity per large square (with a $1 \mathrm{~mm} x$ $1 \mathrm{~mm}$ area) in a Neubauer chamber. 